\title{
Rabbit eyelid conditioning as a function of the intertrial interval '
}

PETER W. FREY AND THOMAS J. MISFELDT UNIVERSITY OF WISCONSIN

Single session conditioning of the rabbit eyelid response was dependent on the intertrial interval (ITI); in general, the shorter the ITI, the greater the mean and variance of the trial at which conditioning began. Conditioning was facilitated by massing the initial CS-US pairings and then continuing training with a spaced trial procedure. No ITI effect was observed with multiple session conditioning.

The relationship between ITI and conditioning rate has not been extensively studied with a classical conditioning paradigm. Spence \& Norris (1950) employed intervals of $9,15,30$, and $90 \mathrm{sec}$ and Prokasy, Grant, \& Myers (1958) used ITIs of 15, 45, and $135 \mathrm{sec}$ in human eyelid studies. Both found that conditioning occurs more rapidly and reaches a higher asymptotic level as the trials are spaced farther apart in time. Recently, Brelsford \& Theios (1965) employed intervals of 45, 111, and $300 \mathrm{sec}$ in studying the effect of the ITI on single session conditioning of the rabbit nictitating membrane. They found that conditioning occurred most rapidly at $111 \mathrm{sec}$ and more slowly at 300 and $45 \mathrm{sec}$. These data did not support the previous findings that conditioning occurs in fewer trials as the ITI is lengthened and the authors suggested that this discrepancy might be related to the detrimental effects of the long sessions used with the 300 sec ITI in their rabbit study.

The present study was designed to provide additional systematic data to evaluate the effect of the ITI in a simple classical conditioning paradigm. The effect of the ITI was studied in both single and multiple session procedures and two ITI shift paradigms were also employed.

Method

The Ss were 88 male, New Zealand white rabbits weighing 4.5 to $6.0 \mathrm{lb}$. Each $S$ was caged individually and had free access to food and water.

The rabbit conditioning equipment has been described in detail previously (Frey \& Ross, 1967a, in press). Essentially, each $\mathrm{S}$ is restrained in a stock and placed in a sound attenuated chamber. Eyelid movements are graphically recorded using a spring return micropotentiometer which is attached to the rabbit's skull. Two stainless steel wire electrodes are sutured just below and to either side of the right eye for presentation of the shock US.

After delivery by a local supplier, the rabbits were habituated according to a standard procedure (Frey \& Ross, 1967a, in press). For all groups the CS was a $1000 \mathrm{~Hz}$ tone, $12 \mathrm{~dB}$ above a constant chamber white noise level of $64 \mathrm{~dB}$ (SPL). The US was a $100 \mathrm{msec}$ $3.6 \mathrm{~mA}$ electric shock delivered to the S's right cheek.
The ITI was the independent variable in the present study and all schedules were variable about a specified average interval. The values of each ITI schedule were multiples of a basic 15 sec schedule which consisted of $9,12,15,18$, and 21 sec intervals.

In scoring the graphical record for each $S$, a CR was defined as a $2 \mathrm{~mm}$ movement of the recording pen between CS onset and US onset in a direction indicating eyelid closure. An electronic pick-off unit was set to automatically record responses which met the above criterion.

\section{Experiment 1}

Eight rabbits were conditioned at each of three different average ITIs-60, 150, and 300 sec. This experiment differed from subsequent work in that multiple session conditioning with a $500 \mathrm{msec}$ interstimulus interval was employed, each animal receiving seven days of acquisition training with 50 trials each day.

The three groups demonstrated similar rates of acquisition (trial of the 30th $C R, 60 \mathrm{sec}=119.4,150$ $\mathrm{sec}=130.1,300 \mathrm{sec}=135.4, \mathrm{~F}<1.0, \mathrm{df}=2 / 21$ ). The data indicated clearly that the intertrial interval was not an important variable in influencing rate of conditioning when long intertrial intervals were interspersed throughout conditioning (multiple session procedure). Experiment 2

Eight rabbits were conditioned at each of six different ITIs-15, 30, 60, 120, 240, and 300 sec. Acquisition was completed in a single session ranging from 2 to $9 \mathrm{~h}$. In this single session procedure a $400 \mathrm{msec}$ ISI was employed to facllitate rapid conditioning (Frey \& Ross, 1967b, in press).

Figure 1 presents a summary of the acquisition data for these Ss. There was a high linear correlation between group means and variances $(r=.97, n=6)$ on the trial of the 30th CR. The ITIs which produced rapid conditioning also produced less variability among the Ss within that group. Because of this correlation between group means and variances, all analyses were computed on the square root transforms of the data. A trend analysis for unequal intervals (Myers, 1966, p. 369) was run on the trial of the 30th CR as a function of $\mathrm{log}$ sec. This analysis indicated a significant linear component $(F=23.4, d f=1 / 42, p<.001)$ and a significant cubic component $(F=10.9$, df $=1 / 42, p<.01)$.

\section{Experiment 3}

Eight rabbits were conditioned at each of two different combinations of a 1 and $4 \mathrm{~min}$ ITI schedule. One group $(1 \rightarrow 4)$ received 20 trials on a $1 \mathrm{~min}$ ITI and was subsequently shifted to the $4 \mathrm{~min}$ schedule. The other 


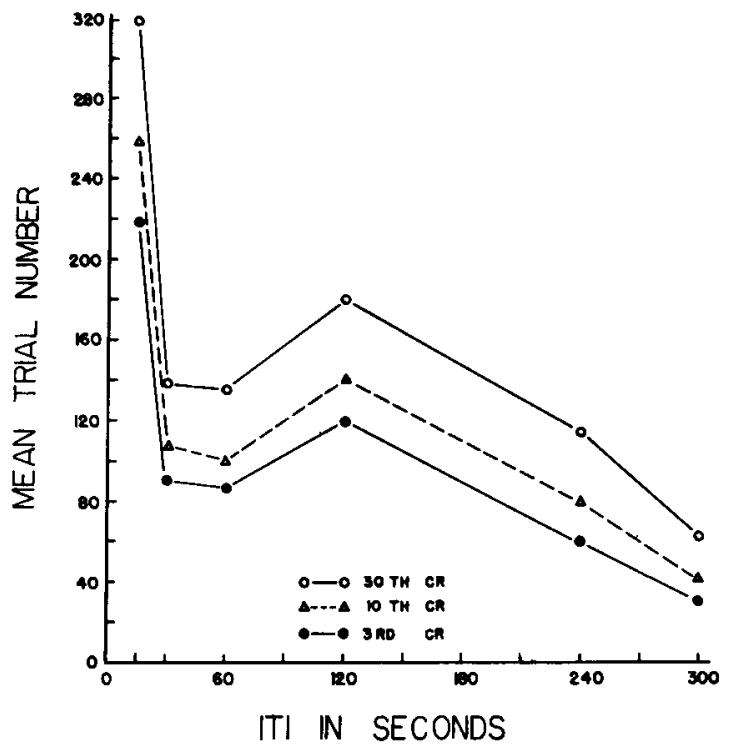

Fig. 1. Single session conditioning of the rabbit eyelid $C R$ as a function of the intertrial interval.

group $(4 \rightarrow 1)$ received 20 trials on the $4 \mathrm{~min}$ ITI and was then shifted to the $1 \mathrm{~min}$ schedule. In all other respects, the conditioning parameters were identical to those employed with the previous single session animals.

The mean trial of the 30th $C R$ for the $4 \rightarrow 1$ and $1 \rightarrow 1$ groups was 185.3 and 136.1 , respectively. The comparable measures for the $1 \rightarrow 4$ and $4 \rightarrow 4$ groups were 99.1 and 114.1 trials, respectively. Conditioning occurred in fewer trials when the Ss were started on a $1 \mathrm{~min}$ ITI $(F=2.91, \mathrm{df}=1 / 28, \mathrm{p}=.10)$ and when they finished on a $4 \mathrm{~min}$ ITI $(F=7.99, \mathrm{df}=1 / 28, \mathrm{p}<.01)$. The interaction between starting and finishing schedules was not significant ( $F=.80, d f=1 / 28$ ). In the beginning relatively massed trials facilitated performance while later in training spaced trials were more effective. Discussion

Temporal spacing of trials was inconsequential when long rest periods were permitted during the acquisition period, i.e., multiple session conditioning. When the ITI was maintained throughout conditioning however, this manipulation was a potent factor in determining rate of acquisition. In single session conditioning, the ITI variable influenced both the mean and variance of the trial at which conditioning first appeared. In general, longer ITIs produced conditioning in fewer trials and reduced within-group variabllity.

The complexity of the ITI function suggests that more than one factor is necessary to account for the relationship between acquisition rate and ITI. Our own preference is to designate two primary influences: (1) a consolidation influence which produces conditioning in fewer trials as a linear function of $\log$ time between trials and (2) an arousal level influence which elicits better performance under conditions of frequent US presentations. The latter influence is probably best approximated as a skewed inverted $U$-shaped function with an optimal US presentation interval at about 30 sec. The combination of these two influences provides a reasonable approximation of the present data.

The order in which different ITIs occur in acquisition is also an important variable. A massed-spaced ITI schedule seems to be much more effective than a spaced-massed order. One interpretation of this effect is to assume that a few initial massed trials are sufflcient to establish and maintain a high arousal level which facilitates both conditioning and performance in the spaced trial procedure which follows.

\section{References}

BRELSFORD, J. Jr., \& THEIOS, J. Single session conditioning of the nictitating membrane in the rabbit: Effect of intertrial interval. Psychon. Sci, 1965, 2, 81-82.

FREY, P. W., \& ROSS, L. E. Differential conditioning of the rabbit's eyelid response with an examination of Pavlov's induction hypothesis. J. comp. physiol Psychol., 1967a, in press.

FREY, P. W., \& ROSS, L. E. Classical conditioning of the rabbit eyelid response as a function of the interstimulus interval. $J$. comp. physioL Psychol, 1967b, in press.

MYERS, J. L. Fundamentals of experimental design. Boston: Allyn and Bacon, 1966.

PROKASY, W. F., GRANT, D. A., \& MYERS, N. A. Eyelid conditioning as a function of unconditioned stimulus intensity and intertrial interval. J. exp. Psychol, 1958, 55, 242-246.

SPENCE, K. W., \& NORRIS, E. B. Eyelid conditioning as a function of the intertrial interval. J. exp. Psychol, 1950, 40, 716-720.

Note

1. This research was supported by a Public Health Service Fellowship, No. 24587, from the National Institutes of Health to PWF and by a National Science Foundation Undergraduate Research Participation Program, GY-833. 